\title{
Formação Acadêmica do Gestor Escolar das Escolas Públicas Municipais Urbanas de Cícero Dantas - BA: Perspectiva Real e Ideal
}

Aline de Santana Santos ${ }^{\prime}$; Maria Leandra Brandão Santos ${ }^{2}$; Hesler Piedade Caffe' Filho ${ }^{3}$

\begin{abstract}
Resumo: Este estudo tem como objetivo trazer uma reflexão sobre a formação acadêmica dos diretores das instituições de ensino da sede do município de Cícero Dantas numa perspectiva real e ideal para atuação do Gestor escolar. Por meio de uma abordagem qualitativa, através da pesquisa empírica feita ao responsável pela Secretaria Municipal de Educação - SEMEC e aos diretores das escolas que estão atuando no momento. Utilizando como base da pesquisa questionários com perguntas objetivas e abertas que pudessem ser respondida com facilidade pelos ocupantes dos cargos. Os resultados demonstraram um distanciamento intermediário entre a formação ideal e a real e os entraves para obtenção da formação sugerida pela Lei de Diretrizes e Bases da Educação Nacional - LDBEN e as políticas públicas propostas pelo Ministério da Educação - MEC. Fornece subsídios para o gestor público municipal e a comunidade escolar e local posicionarem-se de forma criteriosas nas futuras seleções de candidatos ao cargo de diretor escolar, além de auxiliar estudos voltados para problemática semelhantes.
\end{abstract}

Palavras-chave: Formação ideal e real, Aplicabilidade das políticas públicas, Legislação educacional.

\section{Training of School Manager of the Urban Municipal Public Schools of Cicero Dantas- BA: Real Perspective and Ideal}

\begin{abstract}
This study aims to analyze the formation of school management of educational institutions headquarters in the city of Cicero Dantas a real perspective and ideal for school operations manager. Through a qualitative approach, through empirical research done by the responsible City Department of Education SEMEC and school principals who are working at the moment. Using as the basis of survey questionnaires with objective and open questions that could be answered easily by incumbents. The results showed an intermediate distance between the ideal and the real training and barriers to obtaining the training suggested by the Law of Directives and Bases of Education - LDBEN and public policy proposals by the Ministry of Education - MEC. It provides subsidies to the municipal manager and the school and local community to set themselves judicious way in future selection of candidates for school director.
\end{abstract}

Keywords: ideal and real training, Applicability of public policy, educational legislation.

\section{Introdução}

Ao deparar com a temática "formação acadêmica ideal e atual" dos diretores escolares do município de Cícero Dantas de imediato pensa-se na formação ideal dos gestores escolares a nível nacional, quais as políticas de formação, quais avanços e retrocessos.

\footnotetext{
${ }^{1}$ Graduação em Letras pela Faculdade de Ciências Humanas e Sociais - Ages, com habilitação em Português e Língua Portuguesa. Pedagoga pelo Instituto de Educação e Tecnologias - INET. Especialização em Gestão Institucional e Gestão de Pessoas pela Faculdade João Calvino e Pós-graduanda em Gestão Pública pela Universidade Federal do Vale do São Francisco - UNIVASF.

${ }^{2}$ Graduação em Letras pela Faculdade de Ciências Humanas e Sociais de Paripiranga - AGES. Especialização em Língua Linguística e Literatura pelo Núcleo de Pesquisa, Pós-graduação e Extensão da Faculdade Batista Brasileira - FBB - Bahia e, em Língua Portuguesa, pela Faculdade João Calvino. Professora concursada do Colégio Municipal de Antas - Ensino Fundamental II.

${ }^{3}$ Mestre em Gestão de Políticas Públicas.

Autor correspondente: Leandra,brandao@yahoo.com.br.
} 
A legislação educacional nacional, especificamente a Lei de Diretrizes e Bases da Educação Nacional - LDBEN, Lei nº 9.394/1996, afirma que:

Art. 64. A formação de profissionais de educação para administração, planejamento, inspeção, supervisão e orientação educacional para a educação básica, será feita em cursos de graduação em pedagogia ou em nível de pós-graduação, a critério da instituição de ensino, garantida, nesta formação, a base comum nacional. (BRASIL, 1996).

O Ministério da Educação - MEC ciente de que apenas a graduação em pedagogia não é suficiente para gerir um estabelecimento de ensino, ofertou no início do ano de 2005 o Programa Nacional Escola de Gestores da Educação Básica.

De acordo com o portal do Ministério da Educação - MEC, desde o ano de 2006 esse programa avança e apresenta o curso de Pós-graduação (lato sensu) em Gestão Escolar, com carga horária de 400 horas. Em 2009 tem-se a implementação do Curso de Pós-Graduação em Coordenação Pedagógica, para os que fazem parte da equipe gestora.

Dando prosseguimento a formação continuada dos gestores em 2010:

[...] lançou o Curso de Aperfeiçoamento em Gestão Escolar, com carga horária de 200 horas, este curso destina-se aos profissionais de instituições públicas de educação básica da equipe gestora: Diretor e Vice-Diretor, ou o equivalente, nos diferentes sistemas de ensino. Hoje, os cursos estão sendo operados sob a responsabilidade de 31 IPES, atendendo a totalidade dos estados e do Distrito Federal. BRASIL. Portal do Ministério da Educação - Escola de Gestores da Educação Básica. (Disponível em: <http://portal.mec.gov.br/escola-de-gestores-daeducacao-basica/historico> Acesso em: 03 mar2016).

É notório que existe certa preocupação com a formação do diretor escolar, mas que na prática ainda apresenta grandes lacunas e pontos críticos, um deles é a especificação do público-alvo que é apenas para os profissionais da educação que estão em exercício, descartando a possibilidade dos demais de uma mesma instituição se aprimorar para a atuação do cargo de diretor, além do número de participante por escola ser de apenas 2 (dois).

Acrescido a essas falhas tem-se o fato de o cargo acontecer por indicação política desconsiderando todos os pré-requisitos, pois segundo a Lei Municipal 198/2014 fica revogada a Lei Municipal 136/2012 e a Emenda Modificativa Municipal 001/2013 que regularizava a eleição direta para o cargo de diretor escolar. Dessa forma o gestor municipal está autorizado a prover os cargos de diretor e vice-diretor discricionariamente. Fator que acarreta sérios prejuízos ao desenvolvimento da educação do município, no momento da pesquisa desse trabalho apenas um estabelecimento de ensino possui diretor e vice-diretor, os demais funcionam apenas com o diretor. 
O profissional que o sistema nacional de educação investiu atualmente por não fazer parte do quadro efetivo, poderá ser descartado com a nova gestão municipal o que significa "investimento mal direcionado".

Mesmo a LDB explicitando em seu Art, $3^{\circ}$ que o ensino será ministrado segundo o princípio da "Gestão democrática do ensino público, na forma desta lei e da legislação dos sistemas de ensino". O mesmo é desconsiderado no município de Cícero Dantas.

As legislações educacionais necessitam ser mais rigorosas e fixar regras claras, objetivas que não permitam que sejam feitas manobras eleitoreiras como a mencionada acima. A nomeação e exoneração do diretor de escola precisa ter outros parâmetros e critérios mais justos e coerentes com o interesse coletivo da comunidade escolar e não a benefício dos interesses políticos eleitoreiros.

Por assim dizer, o objetivo principal do trabalho é analisar a formação acadêmica real e ideal dos gestores das escolas públicas municipais urbanas de Cícero Dantas - BA. E com os objetivos secundários de: Elencar as Políticas públicas educacionais direcionadas para a gestão escolar e a correlação com o município de Cícero Dantas - Bahia; Analisar a relação entre a Gestão Democrática e o Projeto Político Pedagógico (PPP); Diferenciar Gestão escolar e Administração escolar e paralelamente abordar as Políticas educacionais com foco na Gestão escolar; Verificar os programas adotados pela Secretaria de Educação para a formação do gestor escolar; Analisar a política de escolha dos gestores educacionais municipais.

Do mais, a discussão a ser pautada servirá de apoio para o gestor público municipal que poderá pautar suas novas decisões considerando os itens expostos e evitando as problemáticas sinalizadas, pois é no momento em que se detectam erros e acertos que a educação tende a desenvolver.

\section{Políticas públicas educacionais direcionadas para a Gestão escolar e a correlação com o município de Cícero Dantas - Bahia}

(SCHIMITTER, 1984 apud RUA 2012, p.15) afirma de forma simplória que "a política é a resolução pacífica para os conflitos". (RUA, 1998 apud RUA, p. 15, 2012) complementa que esse é um conceito amplo e é possível delimitar e estabelecer que política é o "conjunto de procedimentos formais e informais que expressam relações de poder e que se destinam à resolução pacífica dos conflitos quanto a bens públicos”. Aprofundando os estudos com Rua (p.17, 2012) é possível depreender que "políticas públicas (policy) são uma das resultantes da atividade política (politics)".

Para compreender o processo educacional é pertinente observar alguns direcionamentos legais, a Constituição Federal em seu Artigo 205 traz a finalidade da educação: 
A educação, direito de todos e dever do Estado e da família, será promovida e incentivada com a colaboração da sociedade, visando ao pleno desenvolvimento da pessoa, seu preparo para o exercício da cidadania e sua qualificação para o trabalho. (BRASIL, 1988).

A LDB, Lei nº 9.394/1996 Art. $2^{\circ}$ afirma que:

A educação, dever da família e do Estado, inspirada nos princípios de liberdade e nos ideais de solidariedade humana, tem por finalidade o pleno desenvolvimento do educando, seu preparo para o exercício da cidadania e sua qualificação para o trabalho. (BRASIL, 1996).

Vale destacar que políticas públicas exige a implantação de ações pautadas em estratégias e determinação nas tomadas de decisão que devem acontecer de forma política e com resoluções pacíficas e para que as mesmas de fato sejam efetivadas é necessário conhecimento teórico e autonomia do gestor.

Nesse aspecto é possível depreender um dos principais entraves na não efetivação das políticas publicas educacionais no município de Cícero Dantas, pois conforme a pesquisa de campo nenhum dos gestores atuante no momento passaram por algum tipo de seleção e/ou capacitação antes de assumirem as direções escolares.

O critério para assumir o cargo de diretor de escola é algo obscuro, as pessoas são escolhidas pelos políticos locais sem a exigência de nenhum pré-requisito. A formação não é considerada, tem-se diretor licenciado em disciplinas específicas como também graduados em pedagogia e todos obtiveram a graduação após a investidura no cargo, já que o mesmo grupo político se mantém no poder há três mandatos eletivos.

Nesse aspecto, percebe-se a falta de perspectiva em buscar uma qualificação para a sua área de atuação, já que o seu cargo independe de qualificação profissional e os mesmos não pertencem ao quadro de funcionários efetivos da rede municipal. Esse fator, de certa forma acarreta empecilhos na efetivação das políticas públicas educacionais voltadas para a formação continuada dos diretores de escolas, os profissionais qualificados atualmente, poderão não fazer parte da educação no futuro.

Em consonância com Lück (2009), fazem-se necessários dentre outros aspectos, que o diretor escolar possua além da formação condizente com a legislação educacional domínio de conhecimento sobre a Constituição Federal, Constituição Estadual, Lei Orgânica Municipal, Lei de Diretrizes e Bases da Educação Nacional, Diretrizes Curriculares Nacionais dos níveis e modalidades de ensino que atua, Legislação Educacional Estadual e Municipal, Estatuto do Magistério, Estatuto da Criança e do Adolescente, instrumentos normativos e executivos de seu sistema e rede de ensino, Concepções e correntes pedagógicas.

Lück (2009, p.25) nos revela: “[...] a formação de gestores escolares passa a ser uma necessidade e um desafio para os sistemas de ensino". E Acrescenta que: 
O trabalho de gestão escolar exige, pois, o exercício de múltiplas competências específicas e dos mais variados matizes. A sua diversidade é um desafio para os gestores. Dada, de um lado, essa multiplicidade de competências, e de outro, a dinâmica constante das situações, que impõe novos desdobramentos e novos desafios ao gestor, não se pode deixar de considerar como fundamental para a formação de gestores, um processo de formação continuada, em serviço, além de programas especiais e concentrados sobre temas específicos. (LÜCK, 2009, p.25)

O Município de Cícero Dantas anda na contramão do almejado na contemporaneidade sobre a gestão escolar a mesma deveria ser democrática e não por intermediação política. O Decreto $\mathrm{N}^{\circ} 6.094$ de 24 de abril de 2007 que Dispõe sobre a implementação do Plano de Metas Compromisso Todos pela Educação expõe no inciso XVIII que cabe aos gestores públicos "fixar regras claras, considerados mérito e desempenho, para nomeação e exoneração de diretor de escola" e que deveria buscar considerar a opinião da comunidade escolar em todo o processo decisório de nomeação e exoneração e pensar na possibilidade de aderir simultaneamente ao processo seletivo e a eleição direta como já ocorre em alguns municípios e no próprio Estado.

\section{Gestão Democrática e o Projeto Político Pedagógico (PPP)}

O PPP é a chave para a gestão democrática da escola, pois nele estão evidenciados os anseios e expectativas educacionais da instituição. A gestão democrática deve consolidar a democracia materializando-se no caráter publico e gratuito da educação e nas buscas permanentes da qualidade de ensino socialmente referenciada para agir na conquista da transformação da escola e da própria sociedade. Por sua vez, é a partir desse conceito de gestão democrática que vai ser possível ter um espaço para evidenciarmos o Projeto político pedagógico.

Paro (2000, p. 67) descreve como essencial a participação do gestor escolar no processo político pedagógico da escola, pois sua atuação pode ter implicações sobre a transformação social, dentro e fora da escola. Pra tanto, é fundamental que a Gestão democrática esteja nas bases do PPP, que seja mais que uma meta, mas uma realidade a ser alcançada pela instituição de ensino.

Hora (2012), por sua vez, traz o PPP como um instrumento da gestão democrática, ou seja,

[...] elaborar o projeto político-pedagógico de uma escola significa mobilizar toda a comunidade escolar em todo de um grande movimento que vise à transformação global da escola: um trabalho que identifique as condições reais da escola e, também, as condições ideias de trabalho para todos. (p. 53)

Do mais, 
O princípio fundante dessa ação compromete-se com práticas educativas que possam ampliar, aprofundar e dar consistência à compreensão de que a construção do projeto político-pedagógico só poderá manifestar-se no seu significado legítimo e pleno se estiver no contexto da gestão democrática. Do mesmo modo, apenas o exercício democrático na gestão da escola possibilitará a vivencia de um projeto pedagógico político, criativo, consciente e coerente com a formação crítica, construtiva e inclusiva de homens e mulheres. (HORA, 2012, p. 53)

Uma gestão democrática requer de seus partícipes, para além do diretor escolar, uma ação conjunta entre as partes, com um currículo diferenciado, um regimento escolar, que englobe os anseios da comunidade escolar e, consequentemente a escola terá m projeto democrático. A democracia na escola não deve ser um aparato utópico, mas um fazer real do dia a dia, mesmo que esse fazer não possa ultrapassar muitas das vezes o muro da escola ele deve ser feito como ponto de partida de um fazer social, dinâmico e indissociável da instituição de ensino.

Na prática, observa-se certa contrariedade entre o almejado e o que de fato ocorre, geralmente os PPPs tratam-se de documentos reproduzidos de forma exaustiva e distante das reais necessidades da instituição escolar, além de ser construído sem a efetiva participação dos segmentos representativos da comunidade escolar o que acarreta distanciamento das reais necessidades no âmbito da instituição pertencente.

Veiga traz sua colaboração ao afirmar que: "o projeto político-pedagógico da escola, ao se identificar com a comunidade local, busca alternativas que imprimam dimensão política e social à ação pedagógica.” (2001, p.62).

O ideal é que o PPP seja construído de forma coletiva e conectado com as necessidades de cada escola e que saia das gavetas dos gestores para ser avaliado e redirecionado constantemente em consonância com as exigências latentes e específicas da instituição e dos envolvidos expondo os seus anseios e projeção de aperfeiçoamento para sanar as reais dificuldades.

Veiga (2004) nos revela o significado da construção do PPP:

Construir um projeto pedagógico significa enfrentar o desafio da mudança e da transformação, tanto na forma como a escola organiza seu processo de trabalho pedagógico como na gestão que é exercida pelos interessados, o que implica o repensar de poder da escola (VEIGA, 2004, p. 40).

Vasconcellos nos orienta sobre como deve ser pautada a postura do gestor frente às tomadas de decisões:

[...] Assim é importante ao gestor discutir soluções possíveis e promover negociações, assumir responsabilidades e deixar que os outros também assumam; ser ouvido, mas também ouvir, valorizar os aspectos positivos do grupo, deixando claras as suas intenções para com a escola e zelar pela total transparência de todas as ações. (2002, p.62). 
A atual política de contratação dos dirigentes escolares na cidade de Cícero Dantas interferem no comprometimento e na qualificação dos profissionais que o exercem, pois os mesmo não tem perspectiva de se manterem no cargo, já que a permanência no exercício do cargo independe desses fatores. A nomeação de seus cargos são temporários e estão relacionados com os mandatos eletivos da política local.

\section{Gestão escolar e Administração escolar}

Organizar, administrar, decidir são papéis que se associam ao diretor escolar, uma vez que não se concebe com clareza as suas funções. A escola está emersa numa sociedade capitalista, que visa à obtenção de lucro. Por este viés é que nunca se conseguiu desvincular a gestão escolar da administração de empresas, uma vez que a administração escolar tem seus fundamentos na Teoria Geral da administração, segundo Hora (2012), bebendo da fonte de Taylor, Fayol e Weber. A associação faz com muitas vezes a escola fique isolada do social, engessando-se num artefato vertical de tomadas de decisões e resultados.

Tal perspectiva administrativa segundo Hora contribui:

[...] para que muitos diretores da escola pública venham a se tornar déspotas com seus dirigidos e subservientes aos dirigentes dos órgãos centrais, esquecendo que sua principal função, e a mais importante, é realizar, por intermédio da administração, uma liderança política, cultural e pedagógica, a fim de garantir o atendimento das necessidades educacionais de sua clientela, cuidando da elevação do nível cultural das massas. (HORA, 2012, p. 18)

Hora (2012) continua a relatar,

O diretor de escola, antes de ser um educador comprometido com a formação do educando, depara com situações em que se reduz a mero repassador de ordens, burocrata atado atrás das mesas, assinando papéis de pouco significado para a educação, "capataz de limpeza e organização" do prédio escolar, sendo obrigado a cumprir e fazer cumprir programas educacionais que continuadas vezes não levam em conta o conhecimento da realidade e as necessidades daquela comunidade escolar. (HORA, 2012, p. 18-19)

O que se busca desse indivíduo segundo o referido autor é alguém que não incomode o sistema, que esteja pronto para executar ordens e não tenha de fato um trabalho de educador, um fazer pedagógico que gere a transformação da escola. É neste sentido que urge a necessidade de entender a Administração Escolar. Para Félix (1986) diz: 
[...] a principal função da Administração Escolar é, tornando o sistema escolar cada vez mais uma estrutura burocrática, permitir ao Estado um controle maior sobre a educação, para adequá-la ao projeto de desenvolvimento econômico do país, descaracterizando-a como atividade humana específica, submetendo-a a uma avaliação cujo critério é a produtividade, no sentido que lhe atribui a sociedade capitalista. (FÈLIZ, 1986, p. 176 apud HORA, 2012, p. 43)

Assim, é preciso buscar um sentido educativo para a administração escolar. Como diz Luck, (2000, p. 99), “a gestão não deprecia a administração, mas supera as suas limitações de enfoque dicotomizado, simplificado e reduzido, para atender as exigências de uma realidade cada vez mais complexa e dinâmica".

Por outro lado, percebe-se que a temática sobre gestão democrática tornou-se ao longo dos tempos bastante difundida entre os setores sociais, uma vez que urge uma necessidade pela democratização do ser, seja nos aspectos intelectuais ou empresarias. Assim como descreve Teixeira:

Nos dias de hoje, os termos "participação e "democracia" têm sido amplamente utilizados pelos mais variados setores sociais. É possível encontrar a defesa desses conceitos nos programas de governo de praticamente todos os partidos políticos. Se pudermos considerar esse fato um avanço, dada a tradição autoritária presente na história brasileira, por outro lado, ao avaliarmos os discursos e as práticas efetivas, podemos perceber que, apesar da apropriação dos termos, os significados e suas aplicações políticas e culturais estão amplamente em disputa. Por isso, cada vez mais, faz-se necessário debater e explicitar melhor o sentido que atribuímos àquelas palavras $(2005$, p.7).

Por este viés cabe a escola a incumbência de formar cidadãos críticos, reflexivos e participativos. Favorecendo, por sua vez, a implantação de uma sociedade democrática e de um ambiente participativo, especialmente quando abre as portas da escola para a entrada de toda a população, através de Conselhos Escolares que viabilizam assistência na elaboração de projetos pedagógicos que acoplem saberes sistematizados a saberes populares na formação dos sujeitos participativos.

Para Heloísa Luck,

A gestão escolar constitui uma dimensão e um enfoque de atuação, que objetiva promover a organização, a mobilização e a articulação de todas as condições materiais e humanas necessárias para garantir o avanço dos processos socioeducacionais dos estabelecimentos de ensino [...] (LÜCK, 2009. p. 24).

Neste sentido, a gestão está ligada ao fortalecimento da democratização da escola, em seu aspecto pedagógico, obtendo a participação de todos nas decisões das ações a serem realizadas. Assim, a temática emite disparidades entre Gestão Escolar e Gestão Educacional. 
Gestão educacional, em caráter de ensino amplo e abrangente, do sistema de ensino, e a gestão escolar, referente à escola, constituem-se em área estrutural de ação na determinação da dinâmica e da qualidade do ensino (LÜCK, 2009. p. 15). Assim como BUSS (2008, p. 21) também enfatiza:

\begin{abstract}
A gestão escolar, por sua vez, como própria expressão sugere, situa-se no âmbito da escola e diz respeito a tarefas que estão sob sua esfera de abrangência (...). Assim, é lícito afirmar que a gestão educacional situa-se na esfera macro, ao passo que a gestão escolar localiza-se na esfera micro. Ambas articulam-se mutuamente, dado que a primeira justifica-se a partir da segunda. Noutras palavras, a razão de existir da gestão educacional é a escola e o trabalho que nela se realiza. A gestão escolar, por sua vez, orienta-se para assegurar aquilo que é próprio de sua finalidade - promover o ensino e a aprendizagem, viabilizando a educação como um direito de todos, conforme determinam a Constituição e a Lei de Diretrizes e Bases.
\end{abstract}

Dessa forma:

(...) os gestores escolares, constituídos em uma equipe de gestão, são os profissionais responsáveis pela organização e orientação administrativa e pedagógica da escola, da qual resulta a formação da cultura e ambiente escolar, que devem ser mobilizadores e estimuladores do desenvolvimento, da construção do conhecimento e da aprendizagem orientada para a cidadania competente. Para tanto, cabe-lhes promover a abertura da escola e de seus profissionais para os bens culturais da sociedade e para sua comunidade. Sobretudo devem zelar pela constituição de uma cultura escolar proativa e empreendedora capaz de assumir com autonomia a resolução e o encaminhamento adequado de suas problemáticas cotidianas, utilizando-as como circunstâncias de desenvolvimento e aprendizagem profissional (LUCK, 2009, p. 64).

Por sua vez, a gestão escolar constitui uma dimensão importantíssima da educação, uma vez que, por meio dela, se observa a escola e os problemas educacionais globalmente e se busca, pela visão estratégica e as ações interligadas, abranger, tal como uma rede, os problemas que, de fato, funcionam e se mantêm em rede (LÜCK, 2009. p. 24-25).

A lista das exigências para um diretor de escola conforme os estudos atuais e as reivindicações implícitas da sociedade contemporânea são extensas. Contudo, na prática da realidade do município em análises essas exigências são ignoradas e/ou desprezadas o que reflete diretamente em um trabalho desqualificado e sujeito ao fracasso.

\title{
Método
}

A pesquisa é qualitativa, sendo que Marconi e Lakatos (2003, p. 32) explicam que esse tipo de abordagem busca analisar e interpretar aspectos mais profundos, com ênfase nos processos e nos significados. O método utilizado é o indutivo, porquanto há a finalidade de observar fatos para chegar a uma conclusão. Em se tratando da profundidade, a pesquisa tem como foco o estudo de campo, onde 
foram realizadas 05 (cinco) entrevistas, 01 (uma) com o responsável pela SEMEC e as demais com os diretores escolares da zona urbana do município de Cícero Dantas que nos permitiu uma amostragem real da formação acadêmica e atuação dos dirigentes escolares.

Esse direcionamento da pesquisa pauta-se em Marconi e Lakato (2003, p. 163) "A amostra é uma parcela convenientemente selecionada do universo (população); é um subconjunto do universo".

Por este viés, essa pesquisa pautar-se-á numa análise de dados coletados in lócus., com destaque a formação acadêmica real e ideal dos gestores municipais urbanos de Cícero Dantas - BA. Caracterizando-a segundo Zanella (2012) "Pesquisa aplicada: tem como motivação básica a solução de problemas concretos, práticos e operacionais" (p.70). "Esta pesquisa é também chamada de pesquisa empírica, pois o pesquisador precisa ir a campo, conversar com pessoas, presenciar relações sociais" (ZANELLA, 2012, p.70).

A partir de toda informação coletada, foi possível trazer uma reflexão a respeito da formação acadêmica dos diretores das escolas públicas municipais da cidade de Cícero Dantas-Bahia. O método indutivo possibilitou partir dos resultados apresentados para inferir dados que poderão servir como referência para outros tantos cantos do Brasil que possuem características semelhantes às presentes neste pequeno município baiano.

Uma parte da pesquisa fora bibliográfica, "como o próprio nome diz, se fundamenta a partir do conhecimento disponível em fontes bibliográficas, principalmente livros e artigos científicos" (ZANELLA, 2012. p. 80). A pesquisa bibliográfica caracteriza-se como uma pesquisa realizada em obras elaboradas por outros autores, ou seja, teóricos que escreveram sobre a temática pesquisada. A mesma é indispensável em qualquer tipo de pesquisa, visto que, é através da mesma que o pesquisador passa a entender a temática pesquisada, assim como, é o alicerce fundamental para as suas próprias conclusões, concordando ou discordando com os autores que já escreveram sobre o tema, também é primordial para entender dados históricos, assim como, para acompanhar as evoluções das leis e da sociedade ao longo dos anos. Nesta perspectiva, Lakatos (2003) coloca que, permite ao pesquisador o contato com o objeto estudado, através de referências de outros autores, a cerca da temática debatida

No momento da entrevista a secretaria municipal de educação estava sem nenhum representante para a sua pasta, o então secretário teria sido exonerado. Logo, o questionário foi respondido por uma das servidoras, a sr $^{\mathrm{a}}$.: Fabiana Andrade do Nascimento a qual identificou-se. Ao ser questionada se todos os estabelecimentos de ensino possuem diretor e vice-diretor, nos informou que "Não, no momento apenas uma escola da sede (Monsenhor Galvão) possui vice, as outras possuem apenas diretor".

Ao ser interrogada sobre os critérios considerados para a efetivação do gestor escolar a mesma assinalou que os itens ponderados são: "indicação política e experiência como professor". Outras observações pertinentes dizem respeito a não oferta de cursos preparatórios para os diretores e no que se refere à formação continuada quando expomos que o Ministério da Educação - MEC ciente 
das fragilidades na formação do gestor escolar vem desde o início de 2005 ofertando cursos direcionados para os dirigentes escolares e quais cursos os diretores escolares do município participaram foi citado apenas o "Formação pela Escola".

Desta forma, este estudo assim caracteriza-se por ser uma abordagem também descritiva, pois segundo Gil (2008) descreve as características de determinadas populações ou fenômenos. Aspectos quantitativos também foram observados em alguns questionamentos que se fizeram necessários. Ao entrevistar os diretores constatou-se que 3 (três) possuem graduação em pedagogia, 1 (um) é licenciado em geografia e todos afirmaram terem experiência como professor, também foram unanimes ao responder que a lotação para Diretor fora através de indicação política.

Quando indagados sobre a formação continuada foi possível inferir que os dirigentes escolares têm consciência da importância de manterem-se atualizados, mas não investem recursos próprios para esse beneficio e anseiam que o município dê suporte para a concretização das políticas públicas educacionais voltadas para a formação do diretor disponíveis sejam efetivadas.

O cenário observado através das entrevistas e das vivências durante a coleta dos dados apresentam poucas divergências no reflexo da atuação dos gestores baseados em seus conhecimentos e no que é permissível pela SEMEC e pelo poder executivo local.

\section{Resultados e Discussões}

Após a criação do questionário têm-se as principais colocações e análises. O primeiro questionário foi composto por dez perguntas (abertas e fechadas), que circunscreveram sobre a temática estudada. Tendo as principais respostas: $\mathrm{O}$ município possui dezessete escolas, sendo quatro urbanas, da qual apenas uma escola da sede possui diretor e vice-diretor (Escola Mul. Monsenhor Galvão). Ao ser questionado sobre os pré-requisitos para a contratação a mesma afirmou que a SEMEC segue os critérios da LDBEN (Lei de Diretrizes e Bases da Educacional nacional) que é de possuir graduação em Pedagogia ou em nível de Pós-graduação, mas ao mesmo tempo afirma que existem outros critérios para a contratação, ou seja, através de indicação política ou possuir experiência como professor. No entanto, sabe-se que alguns diretores assumiram os cargos apenas com o nível médio - modalidade normal e que posteriormente cursaram a graduação.

Essa observação vem confirmar o que já fora descrito que não há uma escolha democrática na contratação dos servidores, mas um jogo de poder político que molda as escolhas.

Para Mello,

Como a figura do diretor tem importância estratégica, as formas de escolha do profissional que vai ocupar esse posto precisam ser pensadas com extremo cuidado. 
Este é um campo aberto para experiências inovadoras, desde que combinem critérios de competência profissional com legitimidade de liderança e autoridade consentida (1997, p.98).

E ainda,

Em se tratando da nomeação, o dirigente escolar é escolhido pelo representante político, qual seja o prefeito ou o governador e assume o cargo como um representante do poder executivo na escola. Dessa forma, passa a ser preposto exclusivo da política de comando do momento e tem consciência de que está a serviço dos interesses políticos ou conveniências daquele que o nomeou. Evidentemente que o aspecto priorizado para esta escolha muitas vezes foge da competência e eficácia administrativa ou educacional. Observam-se prioritariamente critérios político-clientelistas que não combinam com autonomia e gestão democrática, temas tão propalados atualmente. (ZERO, 2006, p. 46)

Quanto aos cursos de formação de gestor que o município participa tem-se apenas o Programa formação pela escola, sendo que o principal critério para participação é estarem atuando no cargo. Por outro lado não desenvolve nenhum curso específico para a formação destes profissionais, em âmbito local. Diz também que os diretores possuem autonomia para a tomada de decisão na instituição que faz parte, tendo a SEMEC uma atuação participativa no funcionamento das escolas. Quanto ao principio da Gestão democrática a mesma afirma que é uma prática no município, o que contradiz sobre a nomeação dos cargos, através de Lei municipal que garante ao gestor fazer suas escolhas quanto à indicação dos diretores de escola.

Do mais, garante que todas as escolas possuem um PPP (Projeto político pedagógico), e que “A construção se dá de forma coletiva com orientação da SEMEC. Todos têm acesso, é só querer. O processo de participação se dá, pois já se construiu e possuem conhecimento sobre as metas, são feitas reuniões com todos". (SEMEC)

Dando continuidade o segundo questionário foi composto por 10 questões fechadas e direcionadas para os diretores das Escolas Urbanas do município, que são quatro: Escola Municipal João de Souza Gouveia, Colégio Municipal Monsenhor Galvão, Escola professor Raimunda Neves Aguiar e Escola Municipal Deputado Cícero Dantas.

Ao serem questionados sobre:

\begin{tabular}{|l|c|}
\hline Respostas & Entrevistados \\
\hline Nível Superior & $\mathbf{2}$ \\
\hline Pós-Graduação & $\mathbf{2}$ \\
\hline Mestrado & -- \\
\hline
\end{tabular}

Figura 1 - Respostas dos entrevistados a pergunta: "Formação acadêmica" 
Segue,

\begin{tabular}{|l|c|}
\hline Respostas & Entrevistados \\
\hline Pedagogia & $\mathbf{3}$ \\
\hline Demais Licenciaturas (Qual?) & $\mathbf{1}$ Geografia \\
\hline
\end{tabular}

Figura 2 - Respostas dos entrevistados a pergunta - Curso de formação inicial:

Neste quadro a exceção é do diretor do Colégio Municipal Monsenhor Galvão que é licenciado em Geografia e com especialização em Gestão e Coordenação escolar. O que demonstra uma falha na formação continuada destes gestores. Quanto à lotação de trabalho todos afirmam que foram contratados através de indicação política o que fere o princípio da Gestão democrática.

Tradicionalmente, percebe-se que a escolha e a designação de dirigentes escolares predominantes no sistema escolar público brasileiro não contemplou aspectos democráticos, ao contrário, o dirigente tem sido indicado tanto no nível estadual quanto no municipal para cargos comissionados, popularmente denominados de “cargos de confiança”. (ZERO, 2006, p. 46)

A questão quatro diz sobre a formação continuada,

\begin{tabular}{|l|c|}
\hline Respostas & Entrevistados \\
\hline Sempre & $\mathbf{2}$ \\
\hline Raramente & $\mathbf{2}$ \\
\hline Nunca Participei de nenhum curso de formação continuada & -- \\
\hline
\end{tabular}

Figura 3 - Respostas dos entrevistados a pergunta: Costuma fazer cursos de formação continuada?

Pode-se observar que há uma divisão nas respostas, metade dos entrevistados afirmam que participam raramente e a outra metade dizem que o fazem sempre. Neste quesito há uma discrepância, pois todos fazem parte da mesma rede de ensino.

[...] a formação continuada dos profissionais da educação se consubstancia como o acumulo de conhecimentos para obtenção de um corpo especifico de saberes, que ocorre de forma inicial ou continuada e integra o currículo da formação e, legitima aqueles sujeitos com capacidades socialmente reconhecidas para o exercício profissional. (TEIXEIRA, 2011, p. 55-56)

Ao serem questionados sobre as políticas de formação do gestor (Possui conhecimento sobre políticas educacionais de formação do Gestor escolar?) três dizem que conhecem o Progestão e apenas um desconhece tais políticas, o que direciona que há uma lacuna quanto à formação ideal dos gestores 
escolares. Quanto à oferta do município sobre tais políticas (O município já ofertou alguma política de formação para Gestor escolar?) há uma divisão exata nas respostas, quando afirmam que o município nunca ofertou nenhum programa e sim através do Progestão e Formação pela escola que são iniciativas do governo federal.

Bastos (2005) nos traz revelações significativas sobre a gestão democrática escolar:

A gestão democrática restabelece o controle da sociedade civil sobre a educação e a escola pública introduzindo a eleição de dirigentes de escolares e os conselhos escolares, garante a liberdade de expressão, de pensamento, de criação e de organização coletiva na escola, e facilita a luta por condições materiais para a aquisição e manutenção dos equipamentos escolares, bem como por salários dignos a todos os profissionais da educação. (2005 p.7 e 8).

Os diretores ao serem questionados sobre a gestão democrática foram unanimes em suas respostas, já que todos afirmam que trabalham sobre tal prisma.

\begin{tabular}{|l|c|}
\hline Respostas & Entrevistados \\
\hline Gestão democrática & 4 \\
\hline Administração escolar & - \\
\hline Não percebe a diferença entre os dois fatores citados.l & - \\
\hline
\end{tabular}

Figura 4 - Respostas dos entrevistados a pergunta - Seu trabalho é pautado em:

Porém, acredita-se ser uma situação delicada e difícil de concretizar de fato a gestão democrática, onde não ocorre à eleição de dirigentes escolares a garantia da liberdade está de certa forma atrelada aos interesses do contratante (político que indicou o cargo).

Para Heloísa Luck: “A gestão democrática implica a participação de todos os segmentos da unidade escolar (...)”. (2000, p. 26). A gestão democrática faz parte do verdadeiro exercício da cidadania, pois implica uma ação compartilhada e participativa. Para tanto fora necessário indagar sobre a autonomia da escola.

\begin{tabular}{|l|c|}
\hline Respostas & Entrevistados \\
\hline Total autonomia & - \\
\hline Autonomia parcial & 2 \\
\hline Depende do poder executivo & - \\
\hline As decisões são subordinadas a SEMEC & 2 \\
\hline
\end{tabular}

Figura 5 - Respostas dos entrevistados a pergunta - Quanto à autonomia na tomada de decisão da escola: 
Embora dizem que possuem autonomia parcial ou suas decisões são subordinadas ao SEMEC.. Para que a gestão democrática seja de fato efetuada é preciso que haja a participação da comunidade escolar, ao serem indagados os entrevistados dizem:

\begin{tabular}{|l|c|}
\hline Respostas & Entrevistados \\
\hline Sim & 4 \\
\hline Não & - \\
\hline
\end{tabular}

Figura 6 - Respostas dos entrevistados a pergunta - Seu trabalho é pautado em: Existe participação da comunidade escolar na Gestão da escola?

Quanto à participação da comunidade escolar todos afirmam que existe tal parceria. A escola que trabalha com a comunidade escolar, auxiliando na tomada de decisão tende a crescer, pois o espaço de educação não deve ser fadado aos muros, mas ser um ambiente de acolhida e interação com seus partícipes.

Através da entrevista é possível perceber que há uma formação básica sobre gestão escolar na medida em que conhecem e possuem uma formação mínima, bem como entendem sobre a necessidade da gestão democrática, mas longe da formação ideal. Por meio das leituras aqui composta é preciso que o gestor esteja "antenado" com sua própria formação, que busquem novos saberes para que se obtenha uma formação ideal.

\section{Considerações Finais}

O propósito dessa pesquisa foi a realização de um estudo direcionado para a formação acadêmica dos gestores escolares do município de Cícero Dantas das escolas pertencentes à sede do município: Colégio Municipal Monsenhor Galvão, Escola Municipal Professora Raimunda Neves Aguiar, Escola Municipal João de Souza Gouveia e Escola Municipal Deputado Cícero Dantas, apenas a primeira oferta o ensino fundamental II, as outras 3 (três) ofertam o ensino fundamental I. A perspectiva do presente trabalho foi centrada na formação real e ideal de acordo com as exigências presente nas legislações do sistema educacional brasileiros e as políticas públicas direcionadas para essa finalidade.

As respostas coletadas através dos questionários e as observações visíveis durante a vivência da pesquisa da forma como foram abordadas servem de aparato qualitativo para direcionar o gestor público municipal e a comunidade local e escolar a conhecer e refletir sobre o processo de escolha do diretor de escola e os reais prejuízos em descartar a eleição direta e a seleção pública para o cargo de gestor escolar. 
É lamentável que formação do gestor escolar não seja fator decisório para ocupação do cargo e que a mesma não seja valorizada constantemente através de ofertas via rede municipal tanto para a formação quanto para progressão salarial.

O Sistema Nacional de Educação caracteriza-se como um serviço público de atendimento direto e modalidade sistêmica. Pode-se afirmar também que é uma rede tutelada, pois em consonância com Inojosa (1999, p. 118-119) apud Malmergrim (2010, p.81) Rede tutelada - no âmbito da qual os entes tem autonomia relativa, já que se articulam sob a égide de uma organização que os mobiliza e modela o objetivo comum [...]. No caso a rede de "Educação" está tutelada ao Ministério da Educação - MEC que é um órgão do governo federal criado através do "Decreto $\mathrm{n}^{\circ}$ 19.402, de 14 de Novembro de 1930".

No entanto, no município de Cícero Dantas o objetivo comum traçado pelo MEC no que se refere à gestão democrática escolar que está diretamente interligada com a eleição direta para o cargo de diretor escolar é desprezada especificamente com a criação de Lei que garante autonomia ao poder executivo de nomear e exonerar os ocupantes do cargo arbitrariamente sem especificar nenhuma exigência.

Após esse estudo, conseguiu-se observar as fragilidades no que diz respeito às competências técnicas e autonomia dos servidores escolhidos para serem os dirigentes das instituições de ensino da zona urbana em posicionar-se desfavorável ao seu contratante, pois a sua permanecia no cargo implicitamente depende da sua submissão.

A partir das análises também foi possível depreender que as políticas públicas direcionadas para a formação do diretor de escola são direcionadas apenas os profissionais que ocupam o cargo naquele momento e que os posteriores não terão essa mesma formação, poderão "quem sabe" participar de outras se forem ofertadas, mas quais serão os novos critérios para escolhas dos participantes?

Com esse trabalho ficou explícito que a gestão democrática e o PPP são indissociáveis, bem como foi possível compreender a diferença e relação entre administrar e gerir uma escola. E em todos esses aspectos encontramos resíduos de falta de perspectiva para fazer a diferença na atuação profissional e a inércia em trilhar o caminho da busca do desconhecido através da formação continuada.

Por assim dizer, evidenciamos a necessidade de conscientizar a busca pela formação ideal e o trajeto mais coerente para que a melhoria ocorra de forma efetiva e que seus benefícios sejam refletidos na vida do "cidadão" que é o foco e direcionamento do serviço público. 
Id on Line Revista Multidisciplinar e de Psicologia

Id on Line Multidisciplinary and Psychology Journal

\section{Referências}

BASTOS, João Baptista. Gestão democrática. da educação. In: BASTOS, João Baptista Gestão democrática. Rio de janeiro: DP\&A: SEPE. 2005, p. 7-30. $4^{\text {a }}$ edição.

BRASIL. Constituição (1988). Constituição da República Federativa do Brasil. Brasília, DF: Senado, $1988 . \quad$ (Disponível em: http://www.planalto.gov.br/ccivil_03/constituicao/ConstituicaoCompilado.htm. Acesso em 11 mar 2016)

BRASIL. Decreto $\mathbf{N}^{\circ} \mathbf{6 . 0 9 4}$ de 24 de abril de 2007. DOU de 25.4.2007. Disponível em:< http://www.planalto.gov.br/ccivil_03/_Ato2007-2010/2007/Decreto/D6094.htm> Acesso em11 mar 2016).

BRASIL. Decreto $\mathrm{n}^{\mathbf{0}} \mathbf{1 9 . 4 0 2}$, de 14 de Novembro de 1930. (Disponível em: http://www2.camara.leg.br/legin/fed/decret/1930-1939/decreto-19402-14-novembro-1930-515729-

publicacaooriginal-1-pe.html Acesso em: 06 mar. 2016).

BRASIL. Lei no 9.394/1996. Estabelece as Diretrizes e Bases da Educação Nacional. DOU 23.12.1996. (Disponível em: <http://www.planalto.gov.br/ccivil_03/Leis/L9394.htm> Acesso em: 11 mar 2016).

BRASIL. Lei $\mathrm{n}^{\circ}$ 9.394/1996. Estabelece as Diretrizes e Bases da Educação Nacional. DOU 23.12.1996. (Disponível em: http://www.planalto.gov.br/ccivil_03/Leis/L9394.htm Acesso em 11 mar 2016).

BRASIL. Portal do Ministério da Educação - Escola de Gestores da Educação Básica. (Disponível em: 〈http://portal.mec.gov.br/escola-de-gestores-da-educacao-basica/historico〉 Acesso em: 03 mar2016).

BUSS, R. B. P. Gestão Escolar. Indaial - SC: ASSELVI, 2008.

CÍCERO DANTAS. Lei Municipal $\mathbf{N}^{\circ}$ 198/2014, de 19 de fevereiro de 2014. (Disponível em: < http://camaradecicerodantas.ba.gov.br/arquivos_clientes/190/midia/51698.pdf $>$ Acesso em 12 mar 2016).

HORA, Dinair Leal da. Gestão democrática na escola. São Paulo: Papirus, 2012.

GIL, Antonio Carlos. Como elaborar projetos de pesquisa. 4. ed. São Paulo: Atlas, 2008.

LUCK, Heloísa. Dimensões de gestão escolar e suas competências. Curitiba: Positivo, 2009.

LUCK, Heloísa. A escola Participativa: o trabalho do gestor escolar. 4 ed.Rio de Janeiro: DP\&A, 2000 .

MALMEGRIN, Maria Leonídia. Redes Públicas de Cooperação em Ambientes Federativos. Florianópolis: Ciências da Administração/UFSC, 2010.

MARCONI, Marina de Andrade; LAKATOS, Eva Maria. Metodologia científica. 3. ed. rev. amp. São Paulo: Atlas, 2003. 
MELLO, Guiomar Namo. Cidadania e Competitividade: desafios educacionais do terceiro milênio. 6. ed. São Paulo: Cortez, 1997.

PARO, V. H. Administração escolar: Introdução crítica. 9. ed. São Paulo: Cortez, 2000.

RUA, Maria das Graças. Políticas Públicas. Florianópolis: Departamento de Ciências da Administração/UFSC, 2012.

TEIXEIRA, A. C. C. (Org.). Os sentidos da democracia e da participação. São Paulo: Instituto, Pólis, 2005.

TEIXEIRA, M. A. P. Formação para diretor escolar da educação básica: o programa nacional escola de gestores no estado do Paraná. Tese de Mestrado em Educação. Universidade Federal do Paraná. Curitiba, 2011.

VASCONCELloS, Celso S.. Coordenação do Trabalho Pedagógico: do trabalho políticopedagógico ao cotidiano da sala de aula. São Paulo, SP: Libertard, 2002.

VEIGA, Ilma P.A. (Org.). As Dimensões do Projeto Político-Pedagógico. Campinas, 4. ed. SP: Papirus, 2001.

Projeto Político-Pedagógico: Educação Superior. Campinas, SP; Papirus, 2004

ZANELLA, Liane Carly Hermes. Metodologia de estudo e de pesquisa em administração. 2. ed. reimp. - Florianópolis : Departamento de Ciências da Administração / UFSC, 2012.

ZERO, M. A. Diretor de escola: compromisso social e educativo. Tese de Doutorado em Educação. Universidade Estadual de campinas Faculdade de Educação. Campinas - SP, 2006.

\section{Como citar este artigo (Formato ABNT):}

SANTOS, Aline de S.; SANTOS, Maria Leandra B. CAFFE FILHO,Hesler .P.Formação Acadêmica do Gestor Escolar das Escolas Públicas Municipais Urbanas de Cícero Dantas - BA: Perspectiva Real E Ideal. Id on Line Revista de Psicologia, Fevereiro de 2016, vol.10, n.29, p. 166-181. ISSN 1981-1179.

Recebido: 5/02/2016

Aceito: $12 / 02 / 2016$ 